\title{
ECONOMIC GROWTH AND GROWTH LINKAGES IN CHINA 1994-2003
}

\author{
Ari Kokko \\ Stockholm School of Economics, Sweden \\ Christer Ljungwall \\ Stockholm School of Economics, Sweden \\ Patrik Gustravsson Tingvall \\ Stockholm School of Economics, Sweden
}

Working Paper 1
October 2008

Postal address: P.O. Box 6501, S-113 83 Stockholm, Sweden.

Office address: Holländargatan 30 Telephone: +46 87369360 Telefax: +46 8313017

E-mail: japan@hhs.se Internet: http://www.hhs.se/cerc 


\title{
Economic Growth and Growth Linkages in China $1994-2003$
}

\author{
Ari Kokko (Stockholm School of Economics, Sweden) \\ Christer Ljungwall (Stockholm School of Economics, Sweden) \\ Patrik Gustavsson Tingvall (Stockholm School of Economics, Sweden)
}

\begin{abstract}
This paper investigates to what degree neighboring Chinese provinces were linked to each other in terms of economic growth, income levels, and foreign direct investment during the period 1994-2003. When looking at mainland China, we find that both the level of income and the rate of income growth in a province depend on developments in neighboring provinces. However, we find no evidence of any positive interdependence between growth in rich coastal provinces and their immediate inland neighbors. This suggests that there has been little harmonization in economic growth rates between these regions, and that the immediate hinterland of the coastal growth centers might be bypassed as China's manufacturing sector is moving west.
\end{abstract}

JELCODE: F14; F15; O53

Keywords: Domestic integration, growth interdependence, China's Economy

${ }^{*}$ Corresponding author. Patrik Gustavsson Tingvall, Stockholm School of Economics, P.O. Box 6501, Se-113 83 Stockholm, Sweden. E-mail: patrik.gustavsson@hhs.se ph. +468 7369267 


\section{Introduction}

The introduction of economic reforms in the late 1970 marked a new era in terms of China's openness to the global economy with profound policies to improve the country's global competitiveness and trade performance. Since then, the Chinese economy has grown steadily and structural changes have transformed the country from being basically an agricultural economy toward a manufacturing based economy. Several factors contributed to this rapid development, including the move towards economic liberalization, low cost of labor, and advances made in technologies. The economics literature explains well both the short-run and long-run considerations of such determinants for China. Less understood, however, is to what extent economic reform has led to increased domestic integration and how economic growth is transmitted across geographical space. These are relevant questions given the current concern for the substantial income gap between the more developed coastal provinces and China's interior regions: the regionally unbalanced development strategy initiated in the early 1980s was based on the assumption that growth would rapidly be diffused westwards from the coastal provinces that were the first to take advantage of the new opportunities.

While much attention has been devoted to domestic integration and 'trickle-down' effects in China, the extant literature does not provide any clear-cut answers to these questions. Two opposite views are provided by Naughton (1999) and Young (2002). The former argues that inter-provincial trade and especially intra-industry trade in manufactured products is large and thus consistent with national economic integration. In contrast, the latter argues that after two decades of economic reform, China's internal market is still fragmented. Fujita and Hu (2001) suggest that the income differences between the coastal area and the interior are increasing, that there is a strong agglomeration of industrial production to the coastal area, and that a convergence trend can be detected among coastal provinces. They also conclude that biased regional policies have some positive effect but that their role is limited.

Brun et al. (2002), claim that growth in China's coastal provinces does not have a uniform effect on the country, and that the effect on the central region is statistically significant and positive while the effect in the western region is not. Breslin (2000) argues that decentralization has strengthened provincial boundaries as determinants of economic activity in China, and that the country's transition from relative isolationism to relative openness has reduced the importance of external relationships in parts of the country. These results are partly supported by $\mathrm{Xu}$ (2002), who suggests that economic integration between provinces has progressed under reform, but that the process is by no means complete.

Adding a geographical dimension to the analysis, that is the connectedness between 
provinces, Ying (2002) applies an explicit spatial approach and finds that provincial per capita income growth in China is spatially interdependent with neighboring provinces and that this interdependence declines with distance. ${ }^{1} \mathrm{Xu}$ (2002) finds that local factors account for roughly 30 percent of regional growth in per capita income and that local policy therefore plays a substantial role for local development. Poncet (2003) concludes that international opening has occurred in conjunction with internal market fragmentation. Madariaga and Poncet (2007) underline that over the 1990s, not only was China's domestic market fragmentation along provincial borders great, but it also became more severe at least between 1992 and 1997. By combining Local Moran statistics and information on the flow of foreign direct investment (FDI), they also detect spatial clustering and spatial interdependence in both FDI flows and per capita income growth.

There is no doubt that existing work in this field has improved our understanding about domestic integration and diffusion of economic growth in China. However, the geographical pattern of economic development is complex, and more detailed analyses are needed to reach a better understanding of the potential ramifications of economic reform and growth on regional development. This paper contributes by treating economic growth as a multidimensional issue and analyzing inter-provincial growth interdependence in an econometric framework that takes into account a set of local factors as suggested by the neo-classical growth model (Solow, 1970).

Our main argument for taking local factors into account when analyzing growth spillovers is as follows: Growth interdependence may not only be driven by growth spillovers, but two geographical units may co-vary also because they draw on common sources. An example could be access to a common resource, like iron ore. If two provinces are both able to draw on the same resource endowment, they may exhibit seemingly interdependent growth patterns even though no spillovers are present. Hence, logic suggests that analyses of spillovers and growth interdependence must also take into account industry structure and endowments.

Our main conclusion from the first part of the analysis suggest that rich (poor) provinces tend to be clustered more than would be expected if the distribution would have been random, and that provinces benefit from having both rich and rapidly growing neighbors. A noteworthy finding is that we see no signs of increasing growth interdependence during the period of study. Rather, the evidence point at decreasing growth interdependence.

The second part of the analysis, inspired by Demurger et al. (2003), groups developed coastal and metropolitan provinces into a "growth pole" region, while the poorer provinces directly adjacent to the growth pole are categorized as a "hinterland" region. We then use spatial econometrics to analyze both the overall pattern of growth interdependence among all of

\footnotetext{
${ }^{1}$ The conclusion falls back to Tobler's law roughly saying "everything is related to everything but things far away are less
} related". 
China's provinces, as well as the relations between the provinces in the growth pole and its hinterland.

The main results indicate that although China as a whole exhibits a pattern of positive and mutual growth interdependence there is no evidence for positive growth spillovers between provinces belonging to the growth pole and their immediate inland neighbors. Contrary to the overall pattern, members of the growth pole and the hinterland region tend to be relatively independent from each other, or even to exhibit a negative relationship with respect to economic growth. A possible explanation for this puzzling finding could be that the first stage of expansion in the growth pole may have occurred with resources (i.e. labor) imported from the neighboring provinces, and that the subsequent westward expansion of production to some extent bypassed these relatively "depleted" provinces.

The paper is structured as follows: The next section presents a brief introduction to China's reform ideology and some theoretical guidance for the analytical work at hand. The data and an exploratory spatial data analysis are presented in section 3. Results are presented in section 4 and section 5 concludes.

\section{Reform ideology and theoretical guidance}

China's market-oriented reforms introduced in the late 1970s aimed at modernizing the economy and at catching up to the other Asian economies. This marked an essential departure from the political isolation and strategy of regional self-sufficiency that had been applied during the preceding decades. During this period, production decisions had completely neglected principles of comparative advantage, economies of scale, and specialization, with the result that inter-provincial trade was essentially a residual. A major element in the reform process was the gradual withdrawal of government from the allocation, distribution, and pricing of goods and services. Parallel to the diminishing role of planning, the Chinese economy was opened up for international trade and investment. These policies were motivated by the search for dynamic and static gains resulting from increased competition, specialization, and diffusion of new technology. A major element in this process was an uneven geographical prioritization. Some regions were allowed to become rich ahead of others, and development efforts aimed at the most promising regions were considered appropriate (Lin and Liu, 2002). The rationale for this unbalanced development strategy was to channel scarce investment resources into a few key sectors. However, there was a clear expectation that there should be strong connections to adjacent sectors and regions, which would enhance a process of economic development through supply and demand linkages. 


\subsection{Theoretical guidance}

As noted by Litwick and Qian (1998), the question of balanced versus unbalanced growth has been a long-standing item in the theoretical debate on development, and several mechanisms for economic spillover effects between countries or regions have been discussed. The research in this area has evolved significantly since Hirschman (1958) first presented his core-periphery model, which stated that the concentration of manufacturing production to a rich (core) region would first generate polarization as the poorer (peripheral) region fell behind, and thus increase regional economic disparity, and then later, as economic growth proceeded in the core region, cause benefits to trickle down to the peripheral region. The logic behind an unbalanced development strategy that initially focused on developing the industry in a core region was the existence of various interactions between domestic industries (Kelegama and Foley, 1999) ${ }^{2}$. Porter's (1990) theory of the competitive advantage of countries also suggested that there is a mutually beneficial and symbiotic relationship between firms making final outputs and firms supplying inputs for that output.

In an early contribution to the literature, Thoburn (1973) argued that for backward linkages to function properly and be profitable they must be of a certain minimum size, and because export growth is not constrained by the domestic market size, exports are more likely to provide this minimum demand. More recently, the analysis of industrial location and backward linkages has been challenged and further developed by authors such as Krugman (1991 a, b), Krugman (1993) Krugman and Venables (1996), and Venables (1996). Krugman (1993) and Venables (1996) argue that increasing returns, economies of scale, and imperfect competition are far more important than constant returns, perfect competition and comparative advantage as drivers of trade and specialization; and that the externalities (market, technological, etc.) underpinning these increasing returns are neither international nor national in scope, but arise through regional or local agglomeration. Hence, they assume that industrial location and agglomeration are partly random, so that the initial pattern may be a pure coincidence.

Thus, agglomeration forces are basically localization externalities, which tend to lead to local clustering of economic activity. Pecuniary externalities, on the other hand, are more important to large-scale core-periphery patters of economic development within nations, leading to greater divergence between rich and poorer regions. Fujita et al. (1999) also point to the importance of competition and argue that linkage theories only work when returns to production at the level of

\footnotetext{
2 This idea was widely used as a planning tool in developing countries during the import-substitution era in the 1950s and 1960s. Reidel (1976) criticized Hirschman's view on backward linkages for implicitly assuming that demand creates its own supply. Instead, Reidel argued that in a country engaged in international trade, such an assumption would be naïve.
} 
the individual firm are increasing: otherwise, the firm would not concentrate production to the largest market, but rather establish a separate facility to serve each market. Athukorala and Santosa (1997) point to the importance of backward linkages for export-led growth, since the greater the linkages between the export sector and the rest of the economy, the greater the benefits to the economy from export expansion. ${ }^{3}$

\subsection{Spillover effects}

The spillover effects from a growing sector in one location to other locations can be readily described in terms of demand and supply side linkages (externalities). These linkages can appear in a number of forms. Demand linkages may from a growing core may, for example, boost growth in the periphery if firms in the periphery can expand their output by sales to the growing core. Similarly, increasing economic activity in the core region may reduce transaction costs, leading to increased trade across the regional border and higher economic growth.

Supply linkages, which are probably the most common mechanisms for spillover effects in China, can be generated by the transfer of technology via foreign investment or imports, imitation of market institutions, the employment of new managerial skills, and so forth. Supply side linkages may also appear via the use of public capital goods provided by the core region. For example, rapidly increasing exports in the core region may trigger construction of new ports, airports, railways, and roads, which facilitate the growth of both domestic and international trade from the peripheral region.

\section{Data and exploratory spatial data analysis}

The data used in this paper cover the variables traditionally used to analyze the determinants of economic growth and spatial interdependence. The sample consists of 29 provinces in mainland China for the period 1994 to $2003^{4}$. The data are compiled from various issues of the China Statistical Yearbook, and the Comprehensive Statistical Data and Materials on 50 Years of New China. All monetary variables are converted to 1990 constant prices.

In this section we explore whether China's provinces are linked together such that neighboring province show similar patterns with respect to income growth and income levels.

\footnotetext{
${ }^{3}$ In his path breaking work Principles of Economics, Marshall (1920) argued that the decision of where to locate economic activities is affected by technology spillovers. The core of his analysis centered around; (i) knowledge spillovers that are "in the air" (ii), forward and backward linkages and, (iii) labor market pooling. The first two concepts implicitly comprise distance, whereas the size of cities is central to the latter. Reasons to believe that knowledge is locally bounded are conveyed as five 'stylized facts' by Dosi (1988), and is further developed by Feldman (1994), and Baptista and Swann (1998).

${ }^{4}$ China is administratively decomposed into 31 provincial units which fall into three categories: provinces (a total of 22), autonomous regions (a total of 5), and municipal cities (a total of 4). Tibet is excluded from our sample due to data constraints and the province of Chongqing is kept within Sichuzan.
} 
Interdependent provinces typically share similar economic structures and performance, and are clustered together. We first explore this issue by means of Morans' I. When exploring spatial clustering and interdependence, the spatial weight matrix $\mathbf{W}$ plays a central role, as it defines how close geographical units are to each other. The elements of the weight matrix are assumed a priori and tested using statistical methods. Closeness can be defined either in terms of the geographical distance between two units, or by defining units that share borders as being neighbors (first order contiguity). In the exploratory data analysis we apply a first order contiguity matrix $\mathbf{W}$ such that $w_{i j}=1$ if unit $i$ and $j$ share borders and zero otherwise ${ }^{5}$. Additional hypotheses are tested for by defining higher order neighboring matrices.

As previously mentioned, we would expect a clustering of economic activities and growth interdependence among geographical units in close proximity to one another. In this spirit we explore both the degree to which growth in per capita income in one province is affected by the corresponding growth in neighboring provinces and the degree to which there is interdependence with respect to the per capita income level.

\subsection{The evolution of spatial similarity over space and time}

As a point of departure, Figure 1 and Figure 2 depict Moran's I for per capita income and per capita income growth, pooled over the full sample period. A positive value of Morans' I indicates that high (low) values are close to other high (low) values to a greater extent than what would be expected from a random distribution, whereas a negative value indicates a chess-board type of pattern.

[Figure 1 and 2 about here]

Figure 1 and Figure 2 show how the degree of similarity between provinces income level and growth evolve as the distance between them increases. To be precise, the first order neighbor is the one with which you share a common border, while you have to pass through one (two) provinces to reach the second (third) order neighbor. In Figure 1 where we analyze the similarity in income levels, the Morans' I records a value of 0.57 for the first order contiguity and decreases to 0.22 for the second order and is insignificant and close to zero (0.02) for the third order contiguity. Hence, per capita income in a province is closely related to its neighbors' per capita incomes, although this relationship diminishes with the distance between provinces. It is noteworthy that the value of Morans' I is negative for the fourth order contiguity, indicating a

\footnotetext{
${ }^{5}$ For a detailed description on methodology, see Anselin (1988), Anselin and Florax (1995) and Anselin (1995).
} 
negative relation between the levels of per capita income at this stage. We interpret the spatial autocorrelations as follows: When we move horizontally across space, starting from a relatively rich province; the per capita income level falls and, after entering the fourth province we are expected to land in a belt of relatively poor provinces. The results suggest an on average relatively smooth diffusion process, where the spillovers related to per capita income levels do not exhibit any clear spatial disruptions.

Interestingly, the spatial autocorrelations for per capita income growth, illustrated in Figure 2, are somewhat different from the results for per capita income levels, as growth rates are positively and significantly related between provinces regardless of the order of contiguity (although the point estimates generally have lower values). As expected, the closest co-variation is found with the first order neighbors ${ }^{6}$.

Economic reform brought significant changes to the economic landscape inherited from the central planning era. The gradual abolishment of central planning and the parallel introduction of markets have allowed provinces and regions to make better use of their comparative advantages and to increase both domestic and international trade. Significant investments in energy and transportation were done parallel to this development. While most authors agree on the positive impacts of reform, it is debated whether or not it has led to greater domestic integration.

If economic integration makes provinces near each other more similar over time, or if integration makes the linkages between provinces stronger, we would expect an upward trend in Morans' I. Figure 3 displays Morans' I for both the level of per capita income and its growth rates year-by-year for the period 1994-2003. The estimates for per capita income levels show a slight increase in income similarity among provinces and is consistent with the interpretation that income levels have converged over time ${ }^{7}$. Surprisingly, we observe that income growth has tended to become less correlated with that in the neighboring provinces over time. We will discuss some possible reasons for this puzzling finding below.

\section{[Figure 3 about here]}

\subsection{Local analysis of spatial dependence}

The global value of Morans' I gives a picture of the overall connectivity but does not reveal

\footnotetext{
${ }^{6}$ Estimations for Figure 1 and Figure 2 are based on row standardized matrices for the first through fourth order contiguity. Provinces that share borders are first order neighbors. To reach the second, third and fourth order contiguity one has to pass through province by province. Calculations are based 10000 permutations.

${ }^{7}$ Note that this measure is not an optimal tool for investigating income convergence at the aggregated level as it only takes into account neighbors that share borders.
} 
information about where provinces with specific properties are located. Mapping the local Moran statistics allow us to detect isolated areas, hot-spots, and other disruptions from the general pattern. ${ }^{8}$ Figures $4-5$ map the local Moran for the per capita income and per capita income growth for the year 1999 (which is the mid-point in our period of analysis).

[Figure 4-5 about here]

The results confirm most of the previously displayed patterns. Income growth in a province is relatively independent from income growth in neighboring provinces, but levels of income display a closer spatial correlation.

\section{Empirical determinants of economic growth}

\subsection{Local determinants of economic growth}

This section reports results from growth regressions. The initial estimations are based on the neo-classical framework, and control for both physical capital and human capital accumulation. We estimate the following base case equation, to which we subsequently add additional control variables:

$$
\hat{\boldsymbol{y}}_{i, t}=\alpha+\boldsymbol{\beta}_{1}\left(\hat{\boldsymbol{k}}_{\boldsymbol{i}, t}\right)+\boldsymbol{\beta}_{2}\left(\hat{\boldsymbol{L}}_{\boldsymbol{i}, t}\right)+\boldsymbol{\beta}_{3}\left(\hat{\boldsymbol{h}}_{i, t}\right)+\boldsymbol{\varepsilon}_{i, t}
$$

where, $\hat{y}_{i, t}$ is growth in per capita income in province $i$, and time $t . \hat{k}_{i, t}$ is growth in fixed capital, $\hat{L}_{i, t}$ is population growth, $\hat{h}_{i, t}$ is growth in graduates (institutions of higher education) as share of population, $\varepsilon_{i, t}$ is the error term, $\alpha$ is the intercept, the $\beta_{i}$ 's are the coefficients to be estimated, and time (t) runs from 1994 through 2003

The population growth rate variable is the gross population growth rate including net migration flows. The neo-classical model (see e.g. Mankiw, Romer, and Weil, 1992) predicts a negative effect from population growth on per capita income growth. In other words, growing populations ceteris paribus leave less capital per worker and reduce labor productivity and per capita GDP'. In the neo-classical growth model the accumulation of capital raises labor productivity, wages, and GDP per capita. Hence, the expected value of the growth rate of fixed capital is

${ }^{8}$ For more details on local Morans' I, see Anselin (1995).

${ }^{9}$ Notably, some studies such as Fagerberg (1994), Durlauf and Quah (1999) report inconclusive country evidence regarding the impact of population growth on per capita income. The possible endogeniety of population growth has been further discussed in Barro and Sala-i-Martin (1995). There is, however, today no consensus regarding the issue. 
positive $^{10}$. Another important issue is that labor is not homogenous. Instead, workers have different skills, education, and experience, all of which have an impact on productivity. For any given supply of labor, the average productivity of workers is expected to increase with educational attainment. To account for differences in skills, we use the ratio of the provincial flow of graduates (institution of higher education) to total population ${ }^{11}$.

[Table 1 about here ]

As noted in estimation 1 in Table 1, both physical capital and human capital accumulation have a positive effect on per capita income growth, while an increasing as population (as expected) reduces economic growth in per capita terms. Hence, these results support the predictions of the neo-classical model. In the second estimation, and as suggested by Barro and Sala-i-Martin (1995), we add a number of variables conducive to growth. Notably, the results suggest a positive and significant impact of FDI on economic growth, although the estimated coefficient is small. The result is not uncommon for the Chinese case (see e.g, Wen, 2007 and references therein). Generally speaking, FDI may have a positive effect on economic growth because foreign owned multinational companies (MNCs) typically are more efficient than local firms. Foreign owned MNCs may also bring new technology and knowledge that is diffused to local firms, thereby increasing their efficiency.

Results in Table 1 also suggest a negative relationship between the dependence on state-owned enterprises (SOEs) and economic growth. This is also a common result for the Chinese case, although the issue of SOEs and their role in the economy is a complex one. Traditionally, China's economy has been heavily dependent on SOEs, and although the situation is changing rapidly, many of the remaining SOEs operate with soft budget constraints and objective functions given by the state. As a result, these firms may have a negative effect on the allocation of resources in the economy. The estimation also controls for the urban-rural divide by adding the weight of manufacturing industry to regional GDP, with the results indicating that economic growth has been most rapid in the more industrialized provinces.

\subsection{Introducing geography}

In estimation 3 through 6 in Table 1 we introduce geography to the model and analyze how economic growth in a province is related to growth in surrounding provinces. The

\footnotetext{
${ }^{10}$ An alternative measure of capital growth is defined as investments net of capital depreciation.

${ }^{11}$ As there are possible endogeniety problems as well as an obvious time lag between finishing education and making an impact on the labor market, we use one year lagged values.
} 
inter-provincial growth interdependence is taken into account by the estimation of spatial lag models (see, eg., Anselin, 1988). The spatial lag is formulated as follows:

$$
\hat{\boldsymbol{y}}_{i, t}=\boldsymbol{\alpha}+\boldsymbol{\rho} \boldsymbol{W} \hat{\boldsymbol{y}}_{i, t}+\boldsymbol{\beta}_{1}\left(\hat{\boldsymbol{k}}_{i, t}\right)+\boldsymbol{\beta}_{2}\left(\hat{\boldsymbol{L}}_{i, t}\right)+\boldsymbol{\beta}_{3}\left(\hat{\boldsymbol{h}}_{i, t}\right)+\boldsymbol{\varepsilon}_{i, t}
$$

where $\hat{y}_{i, t}$ is growth in per capita income in province $i$ s, at time $t . W^{r}$ is a block diagonal NT x NT row-standardized inverse distance matrix. Row standardizing means that each row sums to one and makes the spatial lag coefficient bounded from above to unity. ${ }^{12}$ This standardization makes the estimated $\rho$ equivalent to an elasticity measure. Introducing the spatial lag implies an endogeniety problem which can be handled using an IV approach ${ }^{13}$. The validity of the instruments is confirmed by the Sargan test-statistic.

As we can see from estimation 3, Table 1, the results give support to the hypothesis of interdependent growth rates. Using inverse distance weights, the estimated coefficient of the lagged spatial growth rate is roughly 0.75 . That is, a one percentage-point increase in the growth rate of per capita income in neighboring provinces raises the growth rate of per capita income by 0.75 percentage-points. In estimation 4 , the model is expanded by adding the degree of SOE and manufacturing dependence (to extract information about the industrial structure) and FDI and openness (to capture business climate and degree of connectivity). The inclusion of these variables lowers the coefficient of the spatial lag from 0.75 to 0.28 . This suggest that in sparsely formulated regression models, the spatial lag $(\rho)$ may pick up the lack of control of quantifiable growth linkages. ${ }^{14}$

In estimations 5 and 6 we replace neighbors' income growth with the income level and investigate whether positive growth spillovers are induced by the neighbors' per capita income levels. The growth enhancing income effect is captured by the variable $\left(W^{r}\right) \ln (y)$ and the results suggest that a ten percent higher per capita income in neighboring provinces raises growth by 0.3 -0.6 percentage points. ${ }^{15}$ These results are in line with results reported for other countries by e.g. Barro and Sala-i-Martin (1995, Table 12.3) while Moreno and Trehan (1997, Table 6) reports a statistically insignificant growth effect of GDP per worker in neighboring countries. ${ }^{16}$

\footnotetext{
${ }^{12}$ In Instrumental Variable (IV)-models the coefficient on the spatial lag may exceed unity. For details, see e.g., Anselin (1988).

${ }^{13}$ Following Anselin (1988), we apply spatial lags of the exogenous variables as instruments.

${ }^{14}$ Substituting the inverse distance matrix for a row standardized first order contiguity matrix lowers the coefficient of the spatial lag, but does not upset the significance of the results, indicating that the findings are robust with respect to choice of distance weight procedures.

${ }_{15}$ Note that the inclusion of the spatial variable makes the significance of FDI and openness disappear.

${ }_{16}$ Alternatively, it is possible to consider estimations of models that allow for catching up or convergence in per capita income. Introducing initial per capita income on the right hand side introduces an endogeneity bias. It is
} 
In Estimation 7 we make a first attempt to analyze whether the diffusion effects of neighbors' growth rates are evenly distributed across space. The costal provinces including Beijing are arguably the engine of China's industrial take-off, and we label these provinces "the growth pole". According to the trickle-down theory, growth in the growth pole is supposed to spread inland. We therefore pick out the immediate inland neighbors to the growth pole, label these provinces "the hinterland", and analyze whether the growth interdependence for the "hinterland" deviates from the overall pattern. Results suggest that (i) the interdependence for the growth pole deviates significantly from the overall patter and (ii) growth in the coastal provinces has a weaker than expected impact on growth in the hinterland. Below we therefore explore the relation between the hinterland and the growth pole provinces in some detail.

\subsection{Linkages between rich provinces and poor neighbors}

The general finding of interdependent growth rates across provinces is consistent with the Chinese reform strategy that assumes that the country's economic development is driven by coastal provinces from where it gradually spreads inland. ${ }^{17}$ However, the geographic pattern of income and growth suggests that the diffusion process has not been homogenous. While the coastal provinces have the highest incomes, the provinces immediately to the west and northwest of the coast actually register lower incomes than provinces further inland. This is not fully consistent with a pattern of development where wealth trickles down in a step-wise fashion from the coast to the nearest inland provinces and then further west.

There are several possible reasons why the diffusion of growth must not necessarily be continuous across space. The most obvious may be geography itself - topography, soil characteristics, climate, and patterns of rainfall are only a few examples of factors that determine how well a province or region is able to take advantage of potential growth spillovers. The fact that the provinces neighboring the coast are more mountainous than provinces further inland may therefore provide part of the explanation for the heterogeneous growth pattern. In addition, it is possible that effects akin to Christaller's Central Place Theory or Von Thunen's localization patterns also influence the diffusion of economic growth. In essence, these theories say that

possible to overcome the endogeneity problem by way of estimating dynamic panel models. However, by differencing out fixed effects, each province is compared with its own time average. Hence, in this set-up, convergence is rather to be viewed as a convergence to the provinces own steady-state (as predicted by the model) rather than cross-sectional, or traditional, convergence. In addition, dynamic GMM estimators are large sample estimators and not optimal for our limited dataset. As a test (results available upon request) we estimated the bias-corrected least square dummy variable estimator for the standard autoregressive panel-data model using the approximations in Bruno (2005), who extends the results by Bun and Kiviet (2003), Kiviet (1999), and Kiviet (1995). As expected, the results where fragile with respect to model formulation and lag structure. Given the limited panel dimension, we leave out the results from the dynamic GMM estimations.

${ }^{17}$ See Ljungwall (2004) and references therein. 
when resources are concentrated to growth poles (or central places), they are largely drawn from the hinterland. This depletion of resources in the hinterland means that it is unlikely that a new growth pole can emerge in the immediate vicinity of an existing growth pole: it is instead likely to be located some distanced away, where it can draw resources from its own hinterland.

Looking more specifically at the coastal provinces and their immediate inland neighbors, it can be noted that the differences between the growth pole and the hinterland are significant. For instance, per capita income is 156 percent higher in the growth pole, while both FDI and capital intensity are more than 200 percent higher. That proximity to the coast is an important factor for foreign trade becomes clear when it is noted that the ratio of export plus imports to GDP is more than 800 percent higher in the growth pole (noting, however, that many firms in the neighboring provinces are indirectly involved in exports through their role as suppliers and subcontractors to coastal exporters).

To examine the interdependence between the growth pole and their inland neighbors, we first modify the concept of neighbor. To be precise, provinces in the growth pole are treated as neighbors to the inland provinces (the hinterland) only. That is, provinces in the growth pole are not considered as neighbors to each other, nor are provinces within the hinterland treated as neighbors to each other. As distance weights we apply the commonly used inverse distance.

Table 2 provides the Moran statistics for per capita income and income growth interdependence between the growth pole and hinterland provinces. Moran's I suggest a significant negative relationship for per capita income in "the growth pole" and "the hinterland". The estimates for income growth are also negative but insignificant. Thus, the Morans' I indicate no positive spatial autocorrelation in income and income growth between the growth pole and the hinterland.

[Table 2. about here]

Continuing and mapping the local Moran statistic for the middle year in our sample (1999) on our restricted part of China verifies the special relation between the growth pole and its hinterland. As shown in Figure 6-7, the local Moran statistics for per capita income display a negative and significant value for most provinces and most of the (negative) significant values are concentrated to the coastal regions. For per capita income growth we find a larger share of insignificant values of the local Moran statistic leaving less room for clear cut inference.

[Figure 6-7. about here] 
To get one step further we relax the one-dimensional approach of Morans' I and proceed by repeating the regression analysis performed earlier for the full sample of Chinese provinces. The advantage of this procedure is that we can, in some detail, analyze the interdependence between the growth pole and its hinterland. The results from regression analysis on this restricted part of China are presented in Table 3.

[Table 3 about here ]

Estimations 1 and 2 in Table 3 provide the results from estimating the neoclassical growth model. The results are in line with those covering the whole of China, with a positive impact on economic growth from capital accumulation, FDI, and manufacturing industry dependence. Population growth and SOEs dependence tend to have a dampening effect on per capita income growth, while the impact of human capital accumulation is less clear.

However, when we compare the spatial interdependence between the growth pole and the hinterland we find some striking differences from what we found for the whole country. First, results from estimations 5 and 6 in Table 3 point to a significant negative income relation between provinces in the growth pole and their inland neighbors. Hence, proximity to a richer province in the growth pole does not seem to yield any particular benefits in terms of per capita income growth for the first-tier inland provinces. This result should be interpreted with some caution since there is a risk that the sampling procedure has a bias: we have selected provinces that were a priori known to differ from each other in terms of income and development levels.

In addition to a negative relation in terms of per capita income levels, estimations 3 and 4 suggest that there is no particular benefit for the hinterland of income growth in the growth pole - the estimated coefficient is negative and significant indicating a negative relation in terms of growth rates. This result should be less sensitive to ex ante sampling bias than the results based on analysis of income levels. Thus, although China as a whole exhibits a pattern of positive mutual growth interdependence, the results in Table 3 suggest that this pattern is significantly weaker (or perhaps even negative) when we look at the growth pole and its immediate inland neighbors. In other words, there does not seem to be any smooth transition of positive spillovers from the coastal provinces to their poorer westward neighbors. A likely reason for this result, as noted earlier, is that the agglomeration of activities to the growth pole has to some extent involved resources from the neighboring provinces. Capital and labor in the hinterland has benefited from employment and investment opportunities in the growth pole, but it appears that the 
consequence has been a relatively weaker development in the hinterland itself, as predicted by Christaller's Central Place Theory.

\section{Summary}

In recent years a debate has evolved in China whether economic reform has led to increased domestic integration and how economic growth is transmitted across geographical space. This is an inherently important question, given that evidence suggests that China has not excelled in terms of the diffusion of economic growth from the more developed coastal regions to China's interior areas, as was the intended rationale for the regionally unbalanced development strategy initiated in the early 1980 s.

This paper has explored to what degree China's provinces are linked together such that neighboring provinces show a similar pattern with respect to economic growth and income levels. As a point of departure, we calculated Morans' I statistics and found support for both spatially autocorrelated income levels and economic growth rates. Perhaps a bit surprisingly, we found that economic growth synchronization has tended to decrease over time during our period of study, 1994-2003. In other words, the relationship between the rate of economic growth in a province and economic growth in its surrounding provinces has weakened.

To be precise, results from our regression analysis suggested that income growth in China's provinces is significantly correlated with growth in neighboring provinces; a one percentage point increase in per capita income growth in neighboring provinces is expected to increase economic growth by 0.28-0.75 percentage points. We further investigated whether having a rich neighbor promotes economic growth. Results indicate that a high per capita income level in a neighboring province has a positive effect on per capita income growth although the coefficient estimate suggests that the impact is only moderate.

A number of observers of China's recent economic development have argued that the country's economic growth is driven by coastal provinces and subsequently spreads inland, an idea consistent with China's initial development strategy. We have investigated this question by extracting 16 provinces consisting of a relatively rich growth pole defined as coastal and metropolitan provinces, and the poorer hinterland region defined as provinces located one step west-wards from the coastal areas. Replicating our initial exercise for this subsample, we found no positive effect from growth in the growth pole to their hinterland. On the contrary, we found a negative relationship suggesting that as growth possibilities diminish in the more exploited coastal regions, economic growth moves on to the more unexploited provinces even further inland. 
Our main conclusion from the first part of the analysis is that rich (poor) provinces tend to be clustered more than would be expected from a random pattern, and that provinces benefit from having both rich and rapidly growing neighbors. The lack of evidence from increasing growth interdependence among neighboring provinces is also noteworthy.

Our main conclusion from the second part is that while China as a whole exhibits a pattern of positive mutual growth interdependence, there is no evidence to support this kind of relation between provinces in the growth pole and their immediate inland neighbors. There does not appear to be any smooth diffusion of positive spillovers from coastal and metropolitan provinces to their poorer neighbors further west.

The results suggest that the geographical development pattern is more complex than what can typically be discerned from the simplest models used in modern economic analysis. While there are clear spatial growth patterns, these do not suggest that growth is diffused smoothly from growth centers to increasingly distant locations. Instead, the growth effects may sometimes bypass neighboring provinces, leading to wave-like diffusion patterns. This pattern could be generated by differences in topography, land productivity, climate, and other geographical factors, but it is also possible that there are more systematic determinants. In this paper, we have suggested that the insights of early economic geography models, like Christaller's Central Place theory and Von Thunen's industry location theory, may be relevant also for the diffusion of growth in the modern Chinese context. More specifically, it is possible that the initial positive effects on the first-tier neighbors - which were not only related to the diffusion of economic activity through demand linkages, but also the migration of labor and capital from the hinterland to the rapidly growing coastal provinces - may have become a relative disadvantage at a later stage. More specifically, the hinterland might have been bypassed at the stage when rising production costs in the coastal provinces started to result in the relocation of labor intensive production further inland. Today, after three decades of growth in the coastal areas and labor migration to the coast, the first-tier inland provinces are simply not able to compete with provinces further inland where labor is more abundant.

\section{References}

Anselin, L., and R., Florax. (1995). New directions in spatial econometrics. (Eds). Springer-Verlag, Berlin.

Anselin, L. (1988). Spatial Econometrics: Methods and Models. Dordrecht: Kluwer Academic Publishers, Dordrecht.

Anselin, L. (1995). SpaceStat Tutorial. A Workbook for Using SpaceStat in the Analysis of Spatial Data. Regional Research Institute. West Virginia University, Morgantown, W.V.

Athukorala, P., and B., Santosa. (1997). 'Gains from Indonesian export growth: do linkages matter?’ Bulletin of Indonesian Economic Studies, Vol. 33 (2). 
Baptista, R., and P., Swann. (1998). 'Do firms in clusters innovate more?'. Research Policy, Vol. 27, Iss. 5.

Barro, R.J, N.G., Mankiw, and X., Sala-I-Martin. (1995). 'Capital Mobility in Neoclassical Models of Growth'. The American Economic Review, March.

Breslin, S. (2000). 'Decentralization, Globalization and China's partial Re-engagement with the Global Economy'. New Political Economy, Vol. 5., No. 2.

Brun, J.F., J.L., Combes, and M-F., Renard. (2002). 'Are there spillover effects between coastal and non-coastal regions in China? China Economic Review, Vol. 13.

Bun, M.J.G., and J.F., Kiviet. (2003). 'On the diminishing returns of higher-order terms in asymptotic expansions of bias'. Economics Letters, Vol. 79, Iss. 2.

Demurger, S., J.D., Sachs, T.W., Woo, S., Bao, G. Chang, and A., Mellinger. (2003). 'Geography, Economic Policy, and Regional Development in China'. Working paper 8897. National Bureau of Economic Research, Cambridge, MA.

Dosi, G. (1988). 'Sources, Procedures, and Microeconomic Effects of Innovation'. Journal of Economic Literature, Vol. XXVI.

Durlauf, S.N., and D.T., Quah. (1999). The new empirics of economic growth, Handbook of Macroeconomics, in: J. B. Taylor \& M. Woodford (ed.), Handbook of Macroeconomics, edition 1, volume 1, chapter 4, pages 235-308 Elsevier.

Fagerberg, J. (1994). 'Technology and International Differences in Growth Rates'. Journal of Economic Literature, Vol. XXXII.

Feldman, M.P. (1994). The Geography of Innovation. Kluwer Academic Publishers, Dordrecht.

Fujita, M., P., Krugman, and A.J., Venables. (1999). The Spatial Economy: Cities, Regions, and International Trade. Cambridge, MA, MIT Press.

Fujita, M., and D., Hu. (2001). 'Regional disparity in China 1985-1994: The effects of globalization and economic liberalization'. The Annals of Regional Science, Vol. 35.

Hirschman, A.. (1958). 'Interregional and international transmission of growth'. iReviews of Economics and Statistics, Vol. 55 (2).

Kelegama, S., and F., Foley. (1999). 'Impediments to Promoting Backward Linkages from the Garment Industry in Sri Lanka'. World Development, Vol. 27, No. 8.

Kiviet., J.F. (1999). Analysis of Panels and Limited Dependent Variable Models. In: Hsiao, C., K., Lahiri, L-F., Lee, M-H., Pesaran (Eds.). Analysis of panels and Limited Dependent Variables. Cambridge University press, Cambridge.

Kiviet., J.F. (1995). 'On bias, inconsistency, and efficiency of various estimators in dynamic panel data models'. Journal of Econometrics, Vol. 68, No. 1.

Krugman, P. (1991 a). Geography and Trade. Cambridge, MA, MIT Press.

Krugman, P. (1991 b) 'Increasing returns and economic geography'. Journal of Political Economy, Vol. 99.

Krugman, P. (1993 a). 'On the relationship between trade theory and location theory'. Review of International Economics, Vol. 1.

Krugman. P., and A.J., Venables. (1996). 'Integration, specialization, and adjustment'. European Economic Rview, Vol. 40.

Lin, J.Y., and P., Liu. (2002). 'Development Strategy and Regional income Disparities in China'. China Center for Economic Research Working Paper Series. WP. 52002.

Litwick, J.M., and Y., Qian. (1998). 'Balanced or Unbalanced Development: Special Economic Zones as Catalysts for Transition'. Journal of Comparative Economics, Vol. 26.

Ljungwall., C. (2004). 'Guangdong: A catalyst for economic growth and exports in Hunan province'. Journal of Chinese Economics and Business Studies, Vol. 2, No. 3.

Madariaga, N., and Poncet, S. (2007). 'FDI in Chinese Cities: Spillovers and Impact on Growth' World Economy, 30(5), 837-862.

Mankiw, N.G., D., Romer, and D.N., Weil. (1992). 'A Contribution to the Empirics of 
Economic Growth'. The Quarterly Journal of Economics.

Marshall, A. (1920). Principles of Economics. London: Macmillan.

Moreno., R., and B., Trehan. (1997). 'Location and the Growth of Nations'. Journal of Economic Growth, Vol. 2, No. 4.

Naughton, B. (1999). How much can regional integration do to unify China's markets? Mimeo, University of California-San Diego.

Poncet, S. (2003). 'Measuring Chinese domestic and international integration'. China Economic Review, Vol. 14.

Poncet., S. (2005). 'A Fragmented China: Measure and Determinants of Chinese Domestic Market Disintegration'. Review of International Economics, 13 (3).

Porter, M.E. (1990). 'The competitive advantage of nations'. Harvard Business Review, Vol. 73-93, March-April.

Reidel, J. (1976). 'A balanced-growth version of the linkage hypothesis: a comment'. Quarterly Journal of Economics, Vol. 90 (2).

Solow, R.M. (1970) Growth Theory: An exposition. 1988 edition, Oxford: Oxford University Press (1970) Growth Theory: An exposition. 1988 edition, Oxford: Oxford University Press.

State Statistical Bureau. (2004). China Statistical Yearbook. China Statistical Publishing House.

State Statistical Bureau. (1999). Comprehensive Statistical Data and Material on 50Years of New China. China Statistical Publishing House.

Thoburn, J.T., (1973). 'Exports and the Malaysian Engineering Industry: A Case Study of Backward Linkage'. Oxford Bulletin of Economics and Statistics, Vol. 35. Iss. 2.

Venables, A.J. (1996). 'Localization of Industry and Trade Performance'. Oxford Review of Economic Policy, Vol. 12, No. 3.

Wen, M. (2007). "Foreign Direct Investment, Regional Geographical Market Conditions, and Regional Development: A Panel Study on China". Economics of Transition, 15(1), 125-151.

Ying, L.G. (2002). 'Measuring the spillover effects: Some Chinese evidence'. Paper in Regional Science, Vol. 79.

Young, A. (2002). 'The razor's edge: distortions and incremental reform in the People's Republic of China'. Quarterly Journal of Economics, 115(4).

Xu., X. (2002). 'Have the Chinese provinces become integrated under reform?' China Economic Review, Vol. 13, Issues 2-3. 


\section{Appendix}

Figure 1. Morans’ I, p.c.i., 1994-2003.

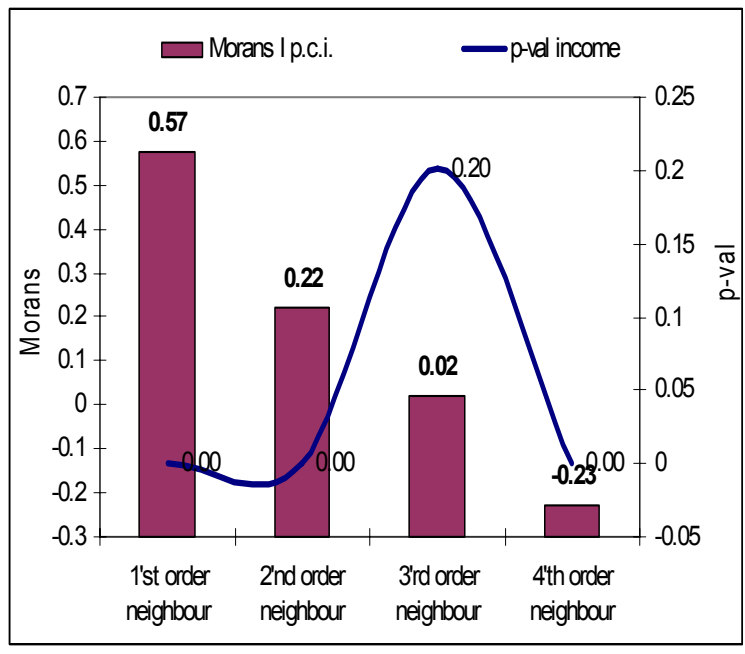

Figure 2. Morans' I, p.c.i growth, 1994 - 2003.

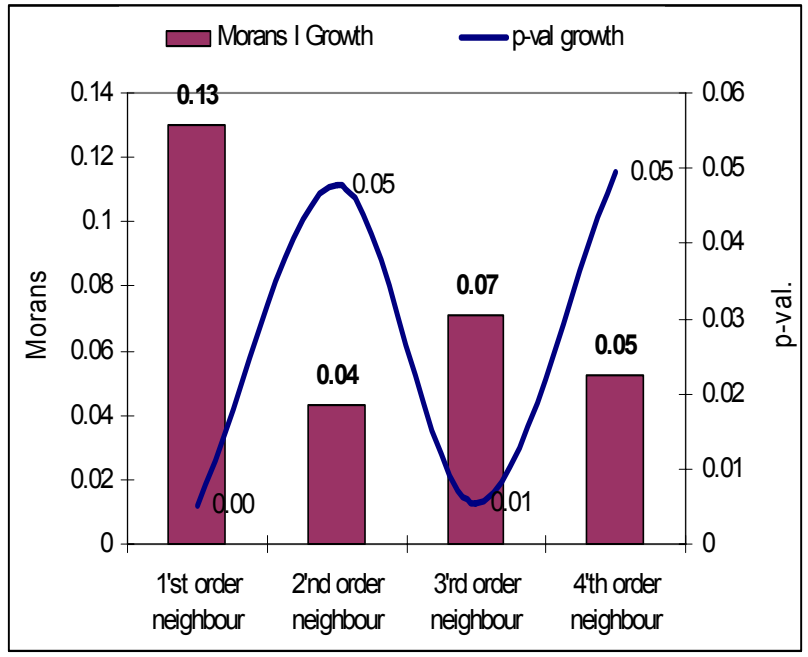

Figure 3. Morans' I for per capita income and income growth, 1994 - 2003.

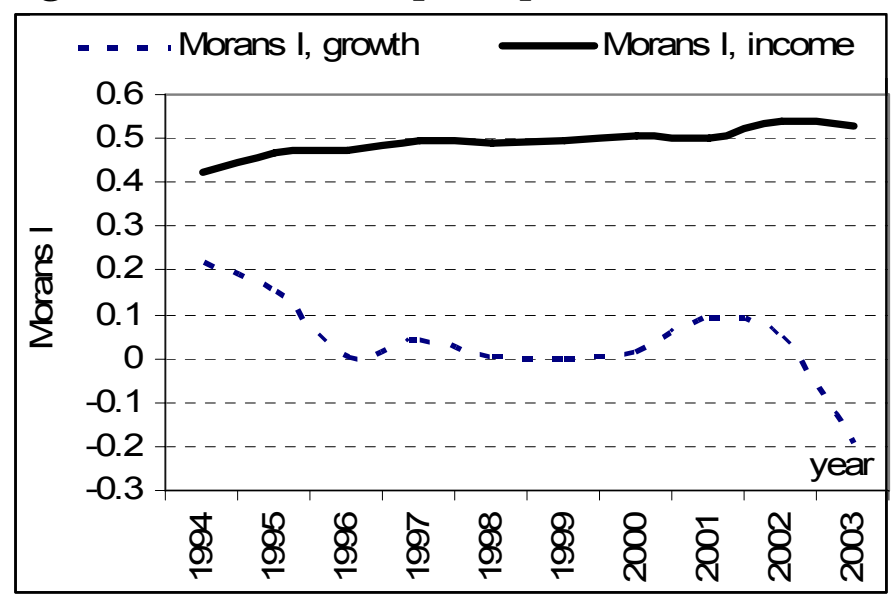


Fig 4. Local Moran, p.c.i growth, 1999.

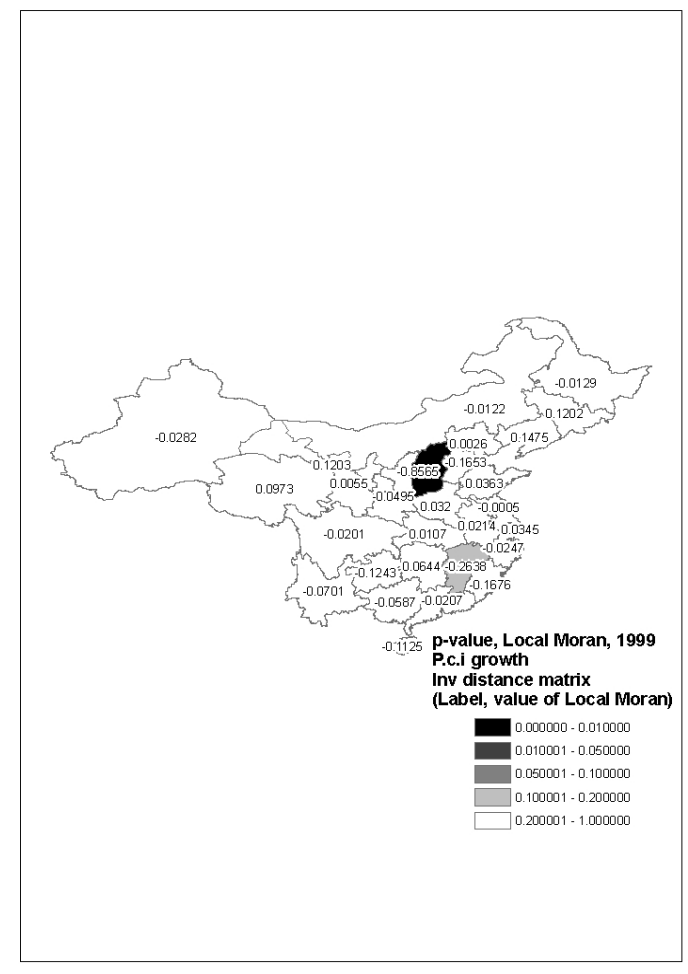

Fig 5. Local Moran, p.c.i, 1999.

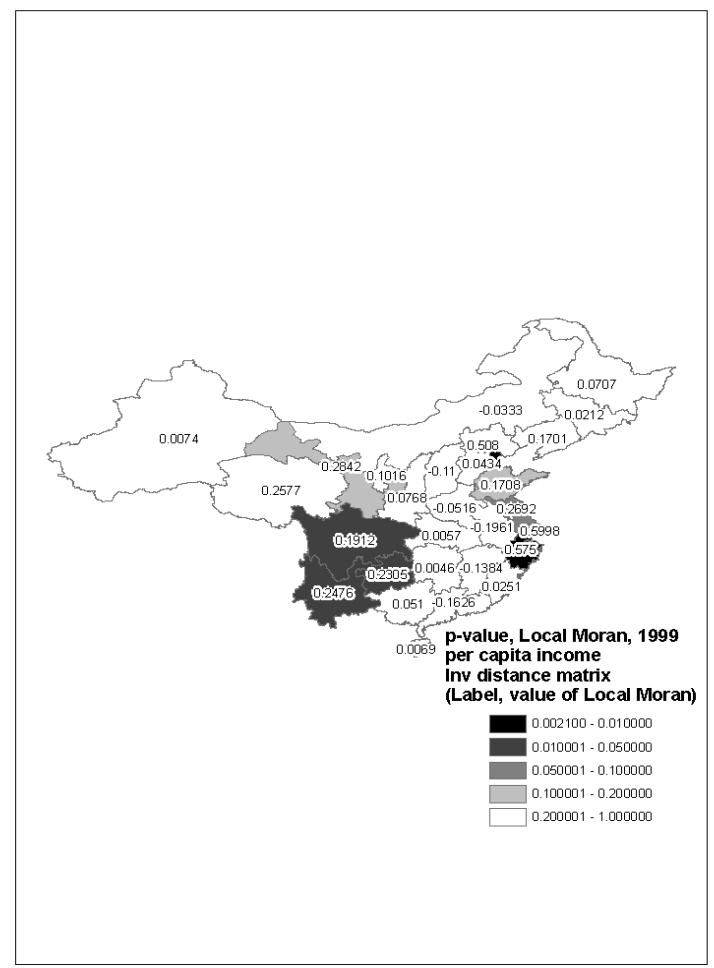


Table 1. Determinants of per capita income growth, 1994-2003.

\begin{tabular}{|c|c|c|c|c|c|c|c|}
\hline Variable & Est 1. & Est 2. & Est 3. & Est 4 & Est 5 & Est 6 & Est 7 \\
\hline Estimator & OLS & OLS & IVFGLS & IVFGLS & IVFGLS & IVFGLS & IVFGLS \\
\hline 1. Population growth $(\mathrm{t})$ & $\begin{array}{l}-0.8258 \\
(0.000)\end{array}$ & $\begin{array}{l}-0.8368 \\
(0.000)\end{array}$ & $\begin{array}{l}-0.8645 \\
(0.000)\end{array}$ & $\begin{array}{l}-0.8697 \\
(0.000)\end{array}$ & $\begin{array}{l}-0.8260 \\
(0.000)\end{array}$ & $\begin{array}{l}-0.8499 \\
(0.000)\end{array}$ & $\begin{array}{l}-0.8682 \\
(0.000)\end{array}$ \\
\hline 2. Capital accumulation $(\mathrm{t})$ & $\begin{array}{l}0.1121 \\
(0.000) \\
\end{array}$ & $\begin{array}{l}0.1085 \\
(0.000) \\
\end{array}$ & $\begin{array}{l}0.1112 \\
(0.000) \\
\end{array}$ & $\begin{array}{l}0.1090 \\
(0.000) \\
\end{array}$ & $\begin{array}{l}0.1136 \\
(0.000) \\
\end{array}$ & $\begin{array}{l}0.1107 \\
(0.000) \\
\end{array}$ & $\begin{array}{l}0.1115 \\
(0.000) \\
\end{array}$ \\
\hline $\begin{array}{l}\text { 3. Human capital } \\
\text { accumulation ( } \mathrm{t}-1)\end{array}$ & $\begin{array}{l}0.0350 \\
(0.011) \\
\end{array}$ & $\begin{array}{l}0.0184 \\
(0.142) \\
\end{array}$ & $\begin{array}{l}0.0350 \\
(0.010) \\
\end{array}$ & $\begin{array}{l}0.020 \\
(0.113) \\
\end{array}$ & $\begin{array}{l}0.0274 \\
(0.037) \\
\end{array}$ & $\begin{array}{l}0.0205 \\
(0.108) \\
\end{array}$ & $\begin{array}{l}0.0372 \\
(0.006) \\
\end{array}$ \\
\hline 4. FDI (t-1) & - & $\begin{array}{l}6.1 \mathrm{e}-08 \\
(0.000)\end{array}$ & & $\begin{array}{l}3.4 \mathrm{e}-08 \\
(0.181)\end{array}$ & & $\begin{array}{l}2.7 \mathrm{e}-08 \\
(0.269)\end{array}$ & \\
\hline 5. SoE share ind output ( $t)$ & - & $\begin{array}{l}-0.0163 \\
(0.073)\end{array}$ & & $\begin{array}{l}-0.0183 \\
(0.046)\end{array}$ & & $\begin{array}{l}-0.0176 \\
(0.047) \\
\end{array}$ & \\
\hline 6. Manu share of GDP ( $t)$ & - & $\begin{array}{l}0.0947 \\
(0.000) \\
\end{array}$ & & $\begin{array}{l}0.0892 \\
(0.000) \\
\end{array}$ & & $\begin{array}{l}0.0694 \\
(0.007) \\
\end{array}$ & \\
\hline 7. openness (t) & - & - & & $\begin{array}{l}0.0368 \\
(0.149)\end{array}$ & & $\begin{array}{l}0.0392 \\
(0.116)\end{array}$ & \\
\hline $\begin{array}{l}\text { 8. Neighbors' p.c.i growth (t) } \\
\text { (inverse dist. matrix) }\end{array}$ & - & - & $\begin{array}{l}0.7474 \\
(0.046)\end{array}$ & $\begin{array}{l}0.2773 \\
(0.406)\end{array}$ & & & $\begin{array}{l}0.7690 \\
(0.039)\end{array}$ \\
\hline $\begin{array}{l}\text { 9. Neighbors' p.c.i (t) } \\
\text { (inverse dist. matrix) }\end{array}$ & - & - & & & $\begin{array}{l}0.0594 \\
(0.000)\end{array}$ & $\begin{array}{l}0.0270 \\
(0.030)\end{array}$ & \\
\hline $\begin{array}{l}\text { 10. Neighbors' p.c.i growth }(\mathrm{t}) \\
* \text { hinterland dum. }{ }^{(\mathrm{A})}\end{array}$ & & & & & & & $\begin{array}{l}-0.0821 \\
(0.180) \\
\end{array}$ \\
\hline Period dum. & yes & yes & yes & yes & Yes & yes & \\
\hline Sargan, p-value & - & - & 0.911 & 0.965 & 0.918 & 0.957 & \\
\hline p-val: var8-var10 =0 & & & & & & & 0.03 \\
\hline Obs & 261 & 261 & 261 & 261 & 261 & 261 & \\
\hline
\end{tabular}

Notes: p-values within parenthesis (.). Replacing the inverse distance matrix for the first order contiguity matrix decreases the coefficient for the spatial variable according to: Mod 1. from 0.75 to 0.07; Mod 2. from 0.29 to 0.09; Mod 3. from 0.06 to 0.03; Mod 4. from 0.03 to 0.02; Mod 5. from 0.96 to 0.25; Mod 6. from 1.06 to 0.39.

(A) Interaction variable between a dummy for provinces immediately to the west of the costal belt provinces, here labeled "the hinterland to the growth pole". 
Table 2. Morans' I. Growth pole and growth receivers, 1994 - 2003.

\begin{tabular}{|l|l|l|}
\hline Variable & Morans' I & p-value \\
\hline Per capita income growth & -0.007 & 0.49 \\
\hline Per capita income & -0.388 & 0.00 \\
\hline
\end{tabular}

Note: Based on bootstrap 10000 permutations.

Figure 6. p-val, local Moran, pci, 16 provinces, 1999. Link matrix.

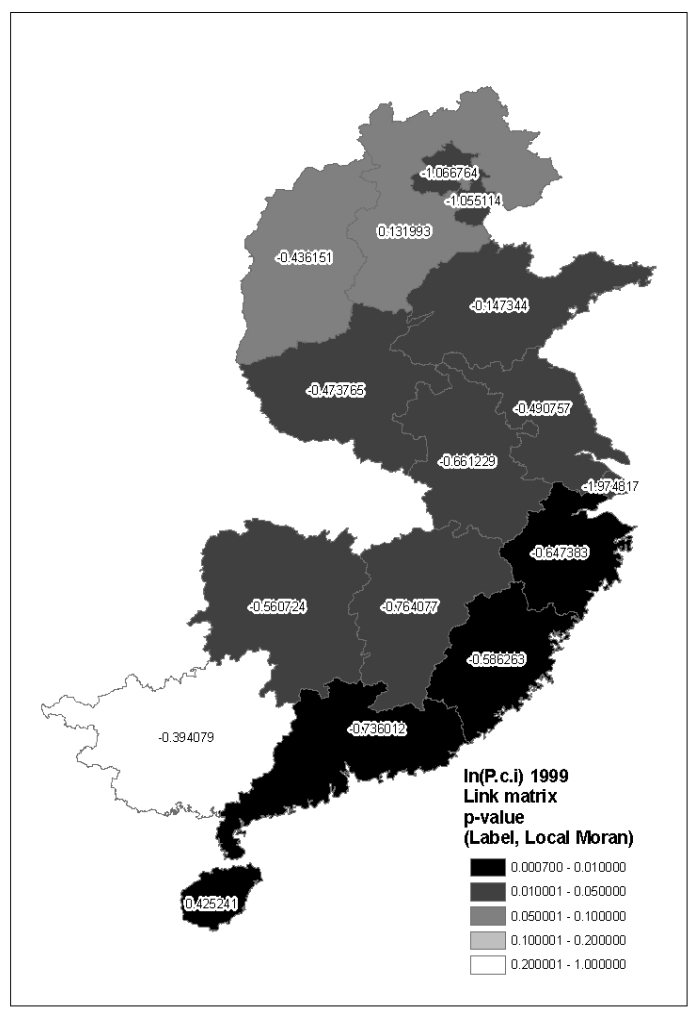

Figure 7. p-val, local Moran, pci growth, 16 provinces, 1999. Link matrix.

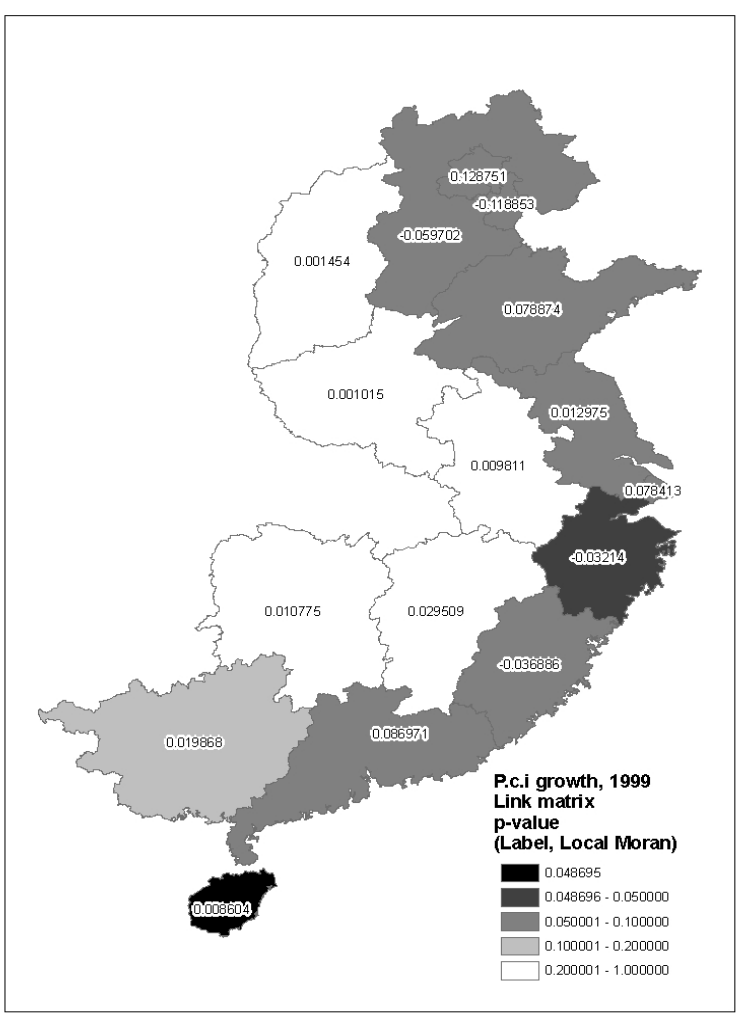


Table 3. Determinants of growth:

Growth pole and hinterland provinces, 1994-2003.

\begin{tabular}{|c|c|c|c|c|c|c|}
\hline Variable & Est 1 & Est 2 & Est 3 & Est 4 & Est 5 & Est 6 \\
\hline Estimator & OLS & OLS & IV-FGLS & IV-FGLS & IV-FGLS & IV-FGLS \\
\hline Population growth (t) & $\begin{array}{l}-0.7981 \\
(0.000) \\
\end{array}$ & $\begin{array}{l}-0.7997 \\
(0.000)\end{array}$ & $\begin{array}{l}-0.8374 \\
(0.000) \\
\end{array}$ & $\begin{array}{l}-0.8503 \\
(0.000) \\
\end{array}$ & $\begin{array}{l}-0.8202 \\
(0.000) \\
\end{array}$ & $\begin{array}{l}-0.8297 \\
(0.000) \\
\end{array}$ \\
\hline Capital accumulation $(\mathrm{t})$ & $\begin{array}{l}0.1067 \\
(0.001)\end{array}$ & $\begin{array}{l}0.1062 \\
(0.001)\end{array}$ & $\begin{array}{l}0.0684 \\
(0.061)\end{array}$ & $\begin{array}{l}0.0981 \\
(0.002)\end{array}$ & $\begin{array}{l}0.0606 \\
(0.078)\end{array}$ & $\begin{array}{l}0.1045 \\
(0.001)\end{array}$ \\
\hline $\begin{array}{l}\text { Human capital } \\
\text { accumulation }(\mathrm{t}-1)\end{array}$ & $\begin{array}{l}0.0224 \\
(0.350)\end{array}$ & $\begin{array}{l}0.0207 \\
(0.363)\end{array}$ & $\begin{array}{l}0.0182 \\
(0.428)\end{array}$ & $\begin{array}{l}0.0208 \\
(0.356)\end{array}$ & $\begin{array}{l}0.0267 \\
(0.271)\end{array}$ & $\begin{array}{l}0.0246 \\
(0.290)\end{array}$ \\
\hline FDI (t-1) & & $\begin{array}{l}4.3 \mathrm{e}-08 \\
(0.072) \\
\end{array}$ & & $\begin{array}{l}3.3 e-08 \\
(0.342)\end{array}$ & & $\begin{array}{l}1.7 \mathrm{e}-08 \\
(0.608)\end{array}$ \\
\hline SoE share of ind output $(\mathrm{t})$ & & $\begin{array}{l}-0.0073 \\
(0.631)\end{array}$ & & $\begin{array}{l}-0.0155 \\
(0.355)\end{array}$ & & $\begin{array}{l}-0.0189 \\
(0.268)\end{array}$ \\
\hline Manu share of GDP $(t)$ & & $\begin{array}{l}0.0868 \\
(0.013)\end{array}$ & & $\begin{array}{l}0.0646 \\
(0.076)\end{array}$ & & $\begin{array}{l}0.0656 \\
(0.105)\end{array}$ \\
\hline Openness ( $\mathrm{t}$ ) & & & & $\begin{array}{l}0.0321 \\
(0.354)\end{array}$ & & $\begin{array}{l}0.0417 \\
(0.239)\end{array}$ \\
\hline $\begin{array}{l}\text { Growth pole - hinterland } \\
\text { growth }(\mathrm{t}) \text { interdependence }\end{array}$ & & & $\begin{array}{l}-1.1242 \\
(0.009)\end{array}$ & $\begin{array}{l}-0.9629 \\
(0.021) \\
\end{array}$ & & \\
\hline $\begin{array}{l}\text { Growth pole - hinterland } \\
\text { p.c.i }(\mathrm{t}) \text { interdependence }\end{array}$ & & & & & $\begin{array}{l}-0.0945 \\
(0.009) \\
\end{array}$ & $\begin{array}{l}-0.0393 \\
(0.338) \\
\end{array}$ \\
\hline Period dummies & yes & yes & yes & yes & Yes & yes \\
\hline Sargan, p-value & - & - & 0.911 & 0.760 & 0.528 & 0.344 \\
\hline Obs & 144 & 144 & 144 & 144 & 144 & 144 \\
\hline
\end{tabular}

Notes: p-value within parenthesis. Growth interdependence between growth receivers and growth pole provinces using the spatial link matrix containing inverse distance weights connecting growth pole provinces only to growth receivers and vice versa (i.e. in this set-up interdependence between growth pole provinces are ignored). Replacing the link matrix for the standard inverse distance matrix decreases the coefficient for the spatial variables according to: Mod 1. from -1.124 to -0.602; Mod 2. from -0.923 to -0.598; Mod 3. from -0.094 to -0.018; Mod 4. from -0.094 to -0.013 ; Mod 5. from -3.487 to -1.764 ; Mod 6. from -2.062 to -0.695 .

For province grouping, see Table A1.

Table A1. Province grouping

\begin{tabular}{lll}
\hline Growth pole provinces & $\begin{array}{l}\text { "Hinterland provinces" } \\
\text { immediately to the west of } \\
\text { the growth pole }\end{array}$ & Other provinces \\
\hline Beijing & Shanxi & Neimenggu \\
\hline Tianjin & Anhui & Liaoning \\
\hline Hebei & Jiangxi & Jilin \\
\hline Shanghai & Henan & Heilongjiang \\
\hline Jiangsu & Hunan & Hubei \\
\hline Zhejiang & Guangxi & Hunan \\
\hline Fujian & & Sichuang \\
\hline Shandong & & Guizhou \\
\hline Guangdong & Yunnan \\
\hline Hainan & Shaanxi \\
\hline & Gansu \\
\hline & Qinghai \\
\hline & Ningxia \\
\hline & & Xinjiang \\
\hline
\end{tabular}

Note: Chongqing is merged into Sichuzan throughout the period of analysis.

Due to missing data Tibet is dropped from the analysis. 